\title{
Public Space in the New Urban Agenda. A Global Perspective on Our Common Urban Future*
}

\author{
Michael W. Mehaffy
}

Ax:son Johnson Foundation, Sweden

michael.mehaffy@gmail.com

\begin{abstract}
This article is a report on the work of our group, the Centre for the Future of Places at KTH Royal Institute of Technology in Stockholm, and its role as an outgrowth of the Future of Places initiative - a partnership of UN-Habitat, the Ax:son Johnson Foundation, and the Project for Public Spaces. The original Future of Places initiative was a series of high-level conferences that brought together over I,500 researchers, professionals, government leaders and activists from 275 organizations in 100 countries. The Future of Places also served as the first Urban Thinkers Campus, contributing to Habitat III and the language of its outcome document, the New Urban Agenda (United Nations, 2017). A primary focus of our series was the central role of public space as the connective framework for healthy urbanization - a point we made clear in the introduction to our "Key Messages" document: The Future of Places affirms the role of public spaces as the essential connective network on which healthy cities and human settlements grow and prosper. Public spaces enable synergistic interaction and exchange, creativity and delight, and the transfer of knowledge and skills. Public spaces can help residents to improve their prosperity, health, happiness and wellbeing, and to enrich their social relations and cultural life... (Future of Places, 2019).
\end{abstract}

Keywords: New Urban Agenda, public space, urban future, UN-Habitat, Centre for the Future of Places

To cite this article:

Mehaffy, M. (2019). Public Space in the New Urban Agenda. A Global Perspective on Our Common Urban Future, The Journal of Public Space, 4(4), I I5-I24, DOI I0.3289I/jps.v4i4. 1236

This article has been peer reviewed and accepted for publication in The Journal of Public Space.

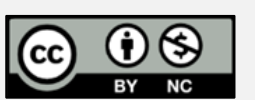

This work is licensed under a Creative Commons Attribution - Non Commercial 4.0 International License https://creativecommons.org/licenses/by-nc/4.0/

\footnotetext{
* This article is an updated text adaptation of a presentation made at the third international conference 'Past Present and Future of Public Space', promoted by City Space Architecture and held at the Venice Architecture Biennale in September 2018, to discuss on 'Knowledge sharing toward implementation of the New Urban Agenda', as part of 'Biennale Sessions', a special program for Universities and Higher Education Institutions.
} 
This article is a report on the work of our group, the Centre for the Future of Places at KTH Royal Institute of Technology in Stockholm, and its role as an outgrowth of the Future of Places initiative - a partnership of UN-Habitat, the Ax:son Johnson Foundation, and the Project for Public Spaces.

The original Future of Places initiative was a series of high-level conferences that brought together over 1,500 researchers, professionals, government leaders and activists from 275 organizations in 100 countries. The Future of Places also served as the first Urban Thinkers Campus, contributing to Habitat III and the language of its outcome document, the New Urban Agenda (United Nations, 2017). A primary focus of our series was the central role of public space as the connective framework for healthy urbanization - a point we made clear in the introduction to our "Key Messages" document:

The Future of Places affirms the role of public spaces as the essential connective network on which healthy cities and human settlements grow and prosper. Public spaces enable synergistic interaction and exchange, creativity and delight, and the transfer of knowledge and skills. Public spaces can help residents to improve their prosperity, health, happiness and wellbeing, and to enrich their social relations and cultural life... (Future of Places, 2019)

We and our collaborators worked very hard to include language in the New Urban Agenda on the importance of public space, and to begin to gather up some of the most significant research on the benefits and challenges of public space - a project that continues today. At this point I am gratified to note that the New Urban Agenda has no fewer than nine paragraphs discussing public space, and outlining its benefits. Among the benefits listed are:

- social interaction and inclusion

- human health and well-being

- economic exchange

- cultural expression

- improving the resilience of cities to disasters and climate change

- physical and mental health

- household and ambient air quality, to reducing noise

- promoting attractive and liveable cities [and] human settlements

- prioritizing the conservation of endemic species.

The New Urban Agenda is also joined by other historic documents of the last few years, including the Sustainable Development Goals and the Paris Climate Agreement. The former also includes an explicit reference to the importance of public space specifically in Target II.7, which states,

By 2030, provide universal access to safe, inclusive and accessible, green and public spaces, in particular for women and children, older persons and persons with disabilities.

To that end, we have been active in helping to develop indicators that will help to benchmark public space and measure progress toward improvement. 
We also participated in the Paris climate conference, COP2I, and presented research on the importance of public space and the linkage to climate-friendly urbanization. That was in fact one of the topics of my own doctoral research at Delft University of Technology some years ago.

The New Urban Agenda also focuses on the link between public space and climate issues, for example in its Article 67:

We commit ourselves to promoting the creation and maintenance of well- connected and well-distributed networks of open, multipurpose, safe, inclusive, accessible, green and quality public spaces, to improving the resilience of cities to disasters and climate change, including floods, drought risks and heatwaves...(United Nations, 20 I 7)

In addition to these kinds of adaptation responses, there is also important research that demonstrates the benefits of public spaces as the central framework for resourceefficient, low-carbon cities for the future. Good quality public spaces, and public space systems, play a key role in walkability, in efficient multi-modal transportation, in active lifestyles and healthy living, and in the liveability and desirability of more compact, resource-efficient urban patterns.

Most of us know this to be true. However, it is one thing to have a general knowledge of these issues, and quite another to be able to implement the goals of the New Urban Agenda and the other related documents. It's quite another to have the persuasive evidence that will convince city leaders to implement, and the tools and strategies that will allow them to do so. Indeed, the last part of the New Urban Agenda focuses on implementation, and in particular:

126. We recognize that the implementation of the New Urban Agenda requires an enabling environment and a wide range of means of implementation, including access to science, technology and innovation and enhanced knowledge-sharing...

149. [Implementation requires] cooperation with subnational and local governments, along with civil society, the private sector, professionals, academia and research institutions, and their existing networks, to deliver on capacity development programmes. This should be done by means of peer-to-peer learning... including the establishment of practitioners' networks and science-policy interface practices... (United Nations, 2017)

This is very much a focus of our efforts now. Among our projects is a database of current research on public space, identifying the work within a number of different disciplines, and what it can tell us about the benefits, the challenges, and the strategies of developing better-quality public space systems in our cities. This is of course an urgent challenge, all the more urgent as the world is urbanizing at a rapid pace.

The alarming news is that much of this urbanization is sprawling, resource-inefficient, and lacking in good quality public space. In fact, in many parts of the world today, even existing public space is under threat, from a range of problems: privatization, erosion from automobiles, invasions of informal settlements, and other disturbing trends. As Dr. Joan Clos, Secretary-General of Habitat III, put it: 
In general, the urban community has become lost in strategic planning, masterplanning, zoning and landscaping ... All these have their own purposes, of course - but they don't address the principal question, which is the relationship in a city between public space and buildable space. This is the art and science of building cities - and until we recover this basic knowledge, we will continue to make huge mistakes. (Clos, 2016)

Dr. Clos therefore calls for nothing less than a "paradigm shift" in understanding urbanization - and he believes the New Urban Agenda represents exactly that. (Clos, 2017) Moreover, he believes that the recovery of the adequate quantity and quality of public space will be essential to this process: "I think that one needs to understand that public space is the origin of urban value." (Clos, 20I8)

How did this loss of public space - this degradation of the core of the urban fabric happen? And what does that say about how we can reverse the trend, and build a new generation of high-quality public spaces, as the New Urban Agenda calls for?

Of course, there were and are strong economic influences, and these must be addressed - a point I will come back to. But the first and most conspicuous issue is the set of professional models of urbanization that we are currently using: models that, as it happens, are now almost a century old. One of the most significant continuing influences is the so-called Charter of Athens, a document developed in 1933 by the highly influential architectural association, the Congres International d'Architecture Moderne, or CIAM, and later published by the architect Le Corbusier.

The Charter of Athens still has a destructive hold on the form of cities today, and in particular their degradation of public spaces, as Dr. Clos, the Secretary-General of Habitat III, has stated. He and his co-authors in the 2018 publication, The Quito Papers (including sociologists Richard Sennett and Saskia Sassen, and planner Ricky Burdett), described the problem: "Despite the increasing complexity and specificity of the global urban condition, many of the 94 recommendations of the 1933 Charter of Athens still determine the generic forms and physical organisation of 2 I st century city" (UN-Habitat, 2018).

Clos and his co-authors went on to describe the problems in this old model for "space and place":

The patterns of urbanization today require a re-framing of the discourse and practice of planning, one that questions the very tenets of the Charter of Athens and challenges the value of anachronistic 'bottom-up vs top-down' models, so heavily rooted in western urbanism. More work is needed to complement the New Urban Agenda, helping to mark a paradigm shift away from the rigidity of the technocratic, generic modernist model we have inherited from the Charter of Athens towards a more open, malleable and incremental urbanism that recognizes the role of space and place--and how they are shaped by planning and design-in making cities more equitable (Clos, Sennett, Burdett and Sassen, 2018).

The problem with the model advanced by the Charter of Athens can best be illustrated by a 1948 drawing by Adolf Bayer, titled "Order and Disorder." It shows the rapturous faith in a new technological city, built on gleaming superhighways and buildings spaced far apart from one another. That "ordered" city would replace the presumed messiness, disease, crowding, and other alleged ills of an older kind of city: 


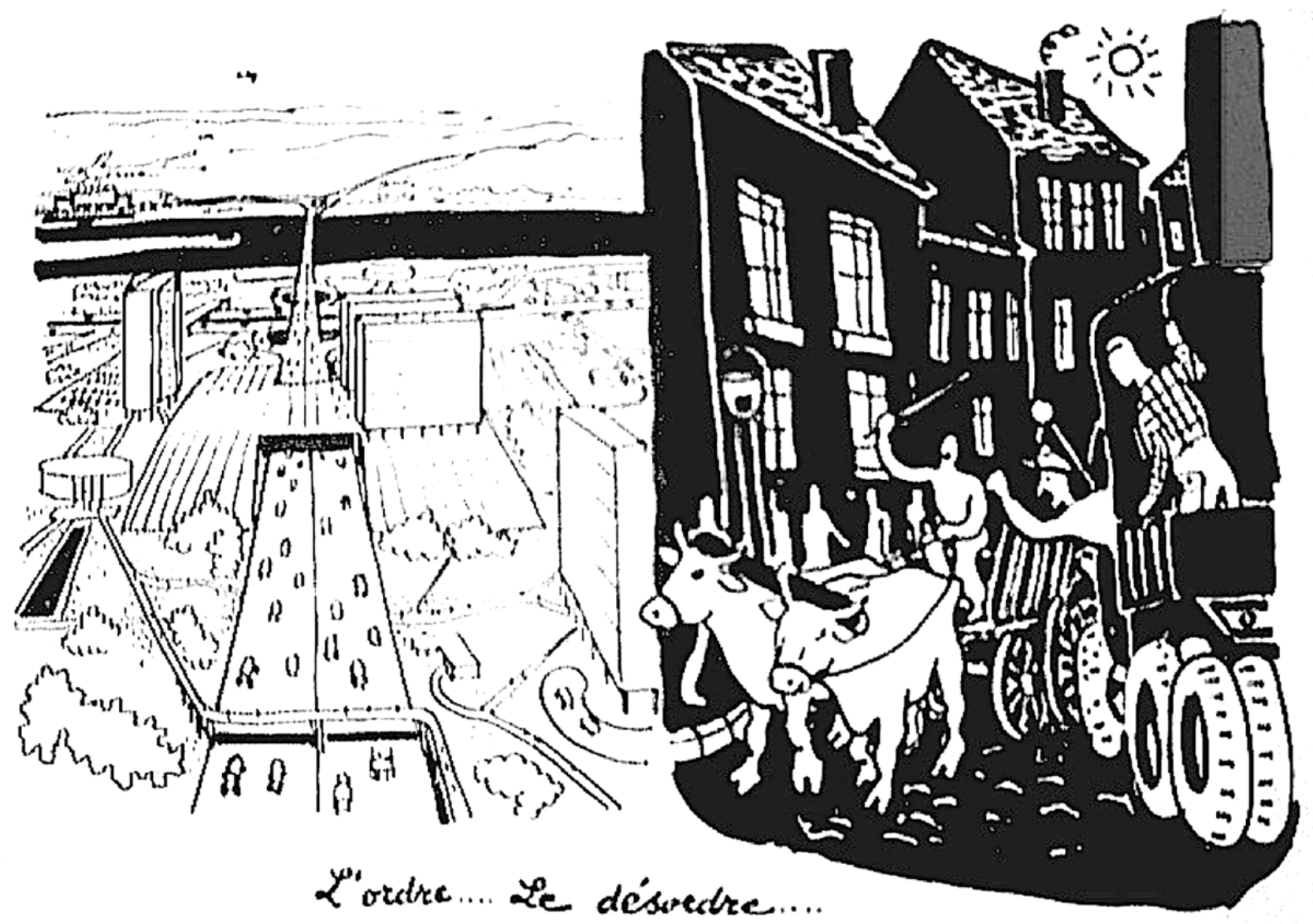

Figure I: Order... Disorder... a 1948 drawing by Adolf Bayer, illustrating the CIAM model of urbanization. Littlenoticed at the time was the impact on a city's public spaces - and its vitality. Image: Public domain.

Of course there were a number of unintended consequences from this model, perhaps most notably the growing dependence on automobiles and other high-resource systems of consumption. Perhaps less noticed was the impact on the city's public spaces, and their power to connect human beings and generate urban synergies. While there were indeed "public spaces" in the new model, they were fundamentally different from the intimately connected, socially dynamic streets and squares of the old city. They were instead only vast areas of greenery, or plazas at the base buildings, or dauntingly long walkways covering large isolated expanses.

What the CIAM proponents failed to realise was that the "messy" street of the old city was in fact a kind of social reactor, compressing people and their activities, and allowing them to mix dynamically, producing spillover benefits in social and economic forms.

The spread-out master plans of the new city (or suburb) produced isolation, sterility, and a dependency on high-resource systems to provide artificial connections. Instead of connecting through the intimate public spaces of a compact neighborhood, we had to connect through the capsules of our cars, to the capsule of our workplaces, from the 
capsules of our homes. This vastly reduced the spectrum of diversity in the kinds of connections that were made.
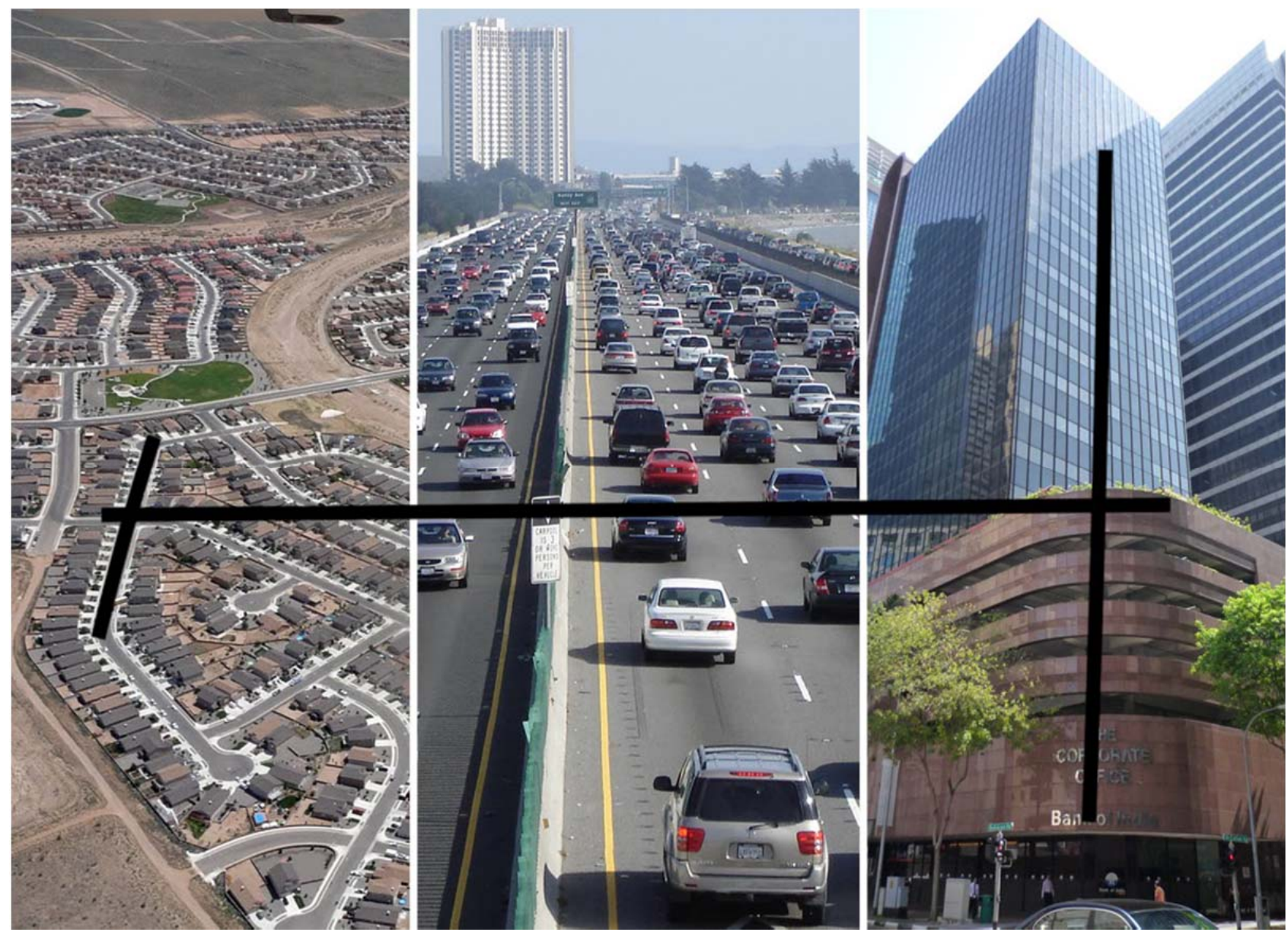

Figure 2. Moving from the "capsule" of our homes, to the "capsule" of our workplaces, through the "capsule" of our cars. The system requires high consumption of resources for a comparatively low economic return - and carries many other negative impacts. Among the most significant is the destruction of public space. Images: Riverrar 303 via Wikimedia Commons; Minesweeper via Wikimedia Commons; Jean-Michel Gobet via Wikimedia Commons.

This was the blueprint for sprawl, and in some ways, it was a smashing success. It has indeed produced great wealth, starting especially in the United States (home of an explosive auto industry, followed closely by the oil industry, the real estate industry, and many others). In many ways, the growth of the American middle class was fueled by this form of urban development.

However, as we are becoming increasingly aware, this sprawl model is fundamentally unsustainable. It relies upon rapid depletion of resources to fuel economic growth, instead of a model that generates wealth in a more sustainable way - for example, by regenerating and "repleting" resources, as some newer models of agriculture do for soil and other resources. In contrast to what we might think of as a "repletion economics," this model is based upon a "depletion economics" - and in spite of the wealth it generates, it cannot be sustained. Given our looming challenges in the years ahead, it 
seems increasingly urgent that we make a transition to a more regenerative "repletion economics."

This model is also highly problematic for those who, for whatever reason, cannot own or operate an automobile - the elderly, the very young, the infirm, or especially, the poor. While the model has produced great wealth for many, it has also left many others in very marginal conditions - even in the wealthiest countries like the United States. It is these people who are most in need of good quality public space. Yet we can certainly understand why leaders in developing countries are urgently seeking models of urbanization and economic development that can create similar levels of wealth, at similarly rapid rates. The conditions of poverty, illness and insecurity they face are profound, and it is unreasonable for wealthy countries to tell them, "we lifted many people out of poverty, but you cannot do the same." Instead, the burden is on us all to develop, as promptly as possible, new models of urbanization that deliver similar economic benefits, without the destructive effects of the sprawl model.
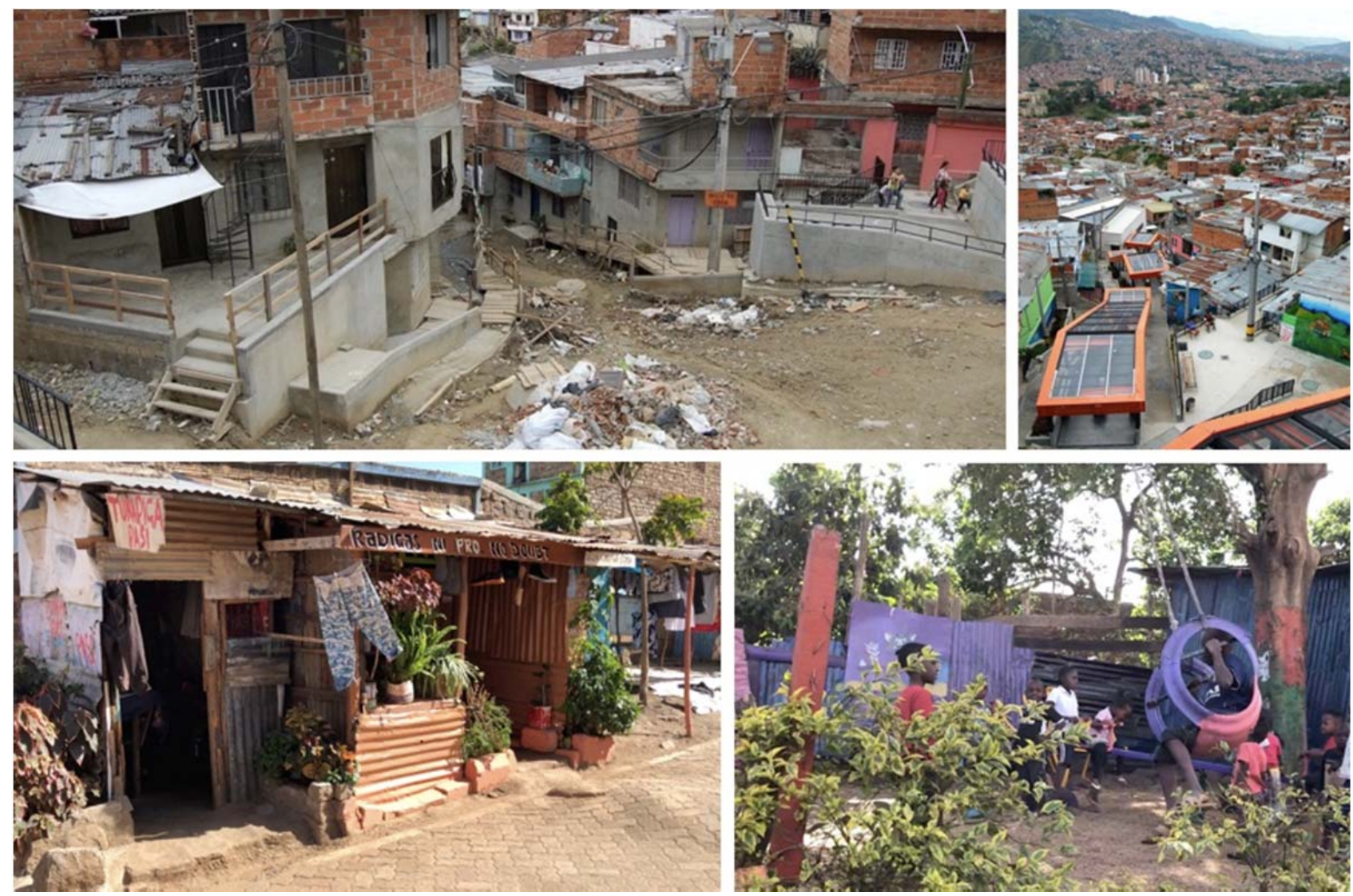

Figure 3. We must recognize the urgent need to overcome poverty and its ills - and at the same time, recognise the inherent capacity of informal settlements to support human growth and well-being through upgrading projects, like Comuna 13 in Medellín (above) and Dandora in Nairobi (below). Photos: the author.

As we're learning from the research, one of the most powerful models of a more sustainable urbanization lies in the natural network power of cities, and the creative expansions they produce - expansions of social interactions, innovations, life 
opportunities, and city wealth. This was a point famously made by the urbanist Jane Jacobs (196I). Interestingly the same research reveals that the best-performing cities, all other things equal, are also the cities that are the most inclusive - that do not cut off or deprive parts of their populations from access and mixing across the city. I wrote about this research recently with my colleague, the anthropologist Setha Low:

As Bettencourt (20/3) and others have shown, a city that excludes large portions of its urban population will under-perform, relative to cities that are more inclusive. This is not only because the excluded populations will tend to demand increasing levels of social service, policing etc. More important, urban economic networks, like other networks, benefit from greater connectivity of larger numbers of nodes, following what is known as Metcalfs Law. (Mehaffy and Low, 2018)
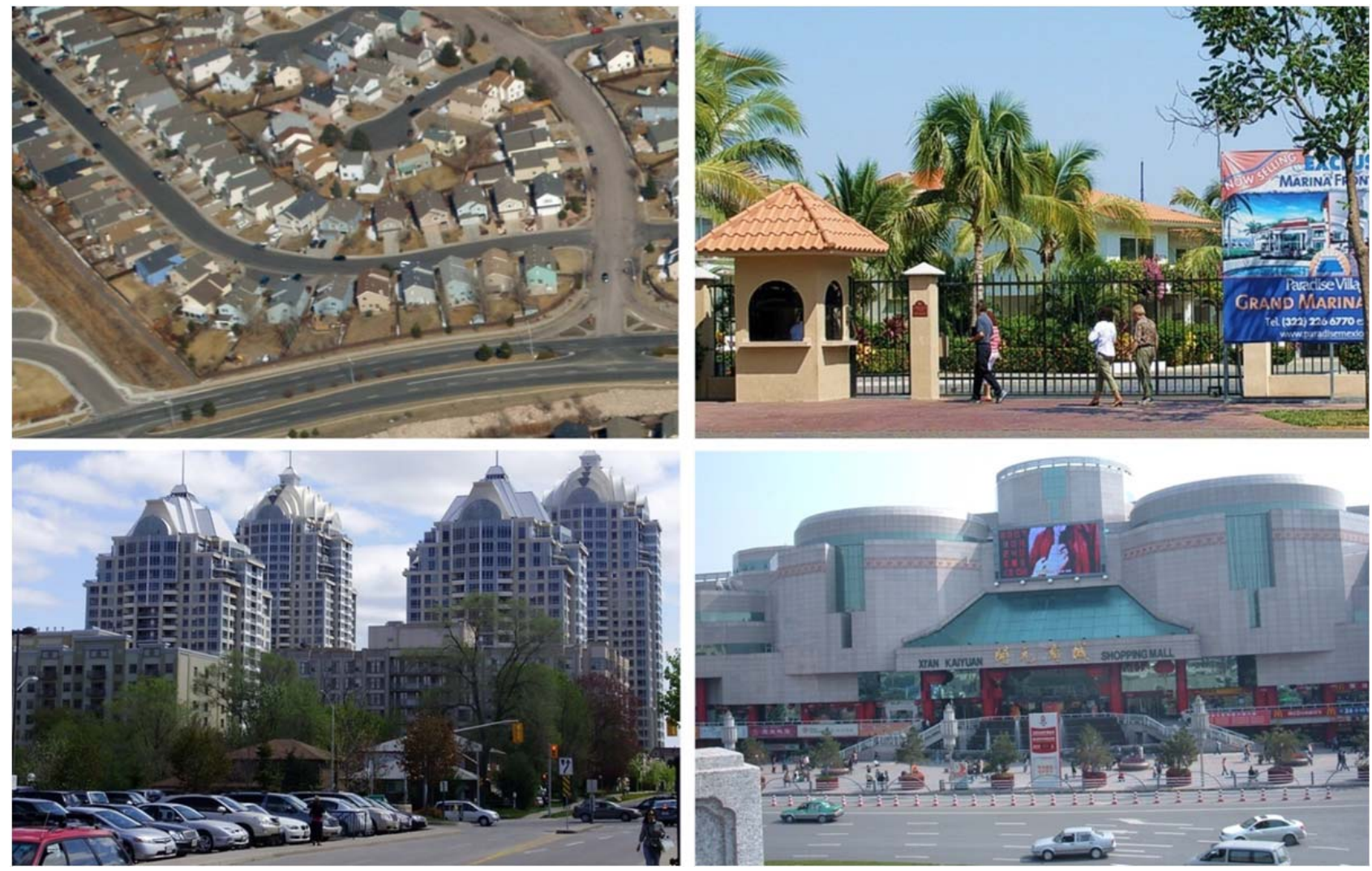

Figure 4. New "market-rate" urbanization is extremely resource-intensive, high-emissions, and exclusionary meaning that it is fundamentally unsustainable. Photos (clockwise from upper right): David Miller via Wikimedia Commons; Coolcaesar via Wikimedia Commons; Brokensphere via Wikimedia Commons; and GTD Aquitaine via Wikimedia Commons.

So it may be that inclusive cities are not only about justice and fairness, but that over time, inclusive cities are better for everyone's bottom line. This is a critical message, offering potentially powerful resources to counter the current rush of quick profits on unsustainable forms of sprawl development that are proceeding around the world today at an alarming pace. 
However, we need tools to change this "operating system for growth" - more specifically, to capture the increased value over time from city networks, using this value to incentivize better-quality development, and especially, better-quality public space systems. There are a number of promising tools emerging to do that - financial tools, public investments, tax policies and other mechanisms. We need to develop these tools, and find ways to share them with one another across very different national and local contexts, often with very different political, legal, cultural and climatic conditions. This is in fact one of the most important parts of the New Urban Agenda: the concluding implementation section that calls for "enhanced knowledge-sharing," "peerto-peer learning," and "open, user-friendly and participatory data platforms using technological and social tools available to transfer and share knowledge among national, subnational and local governments and relevant stakeholders, including non-State actors and people".
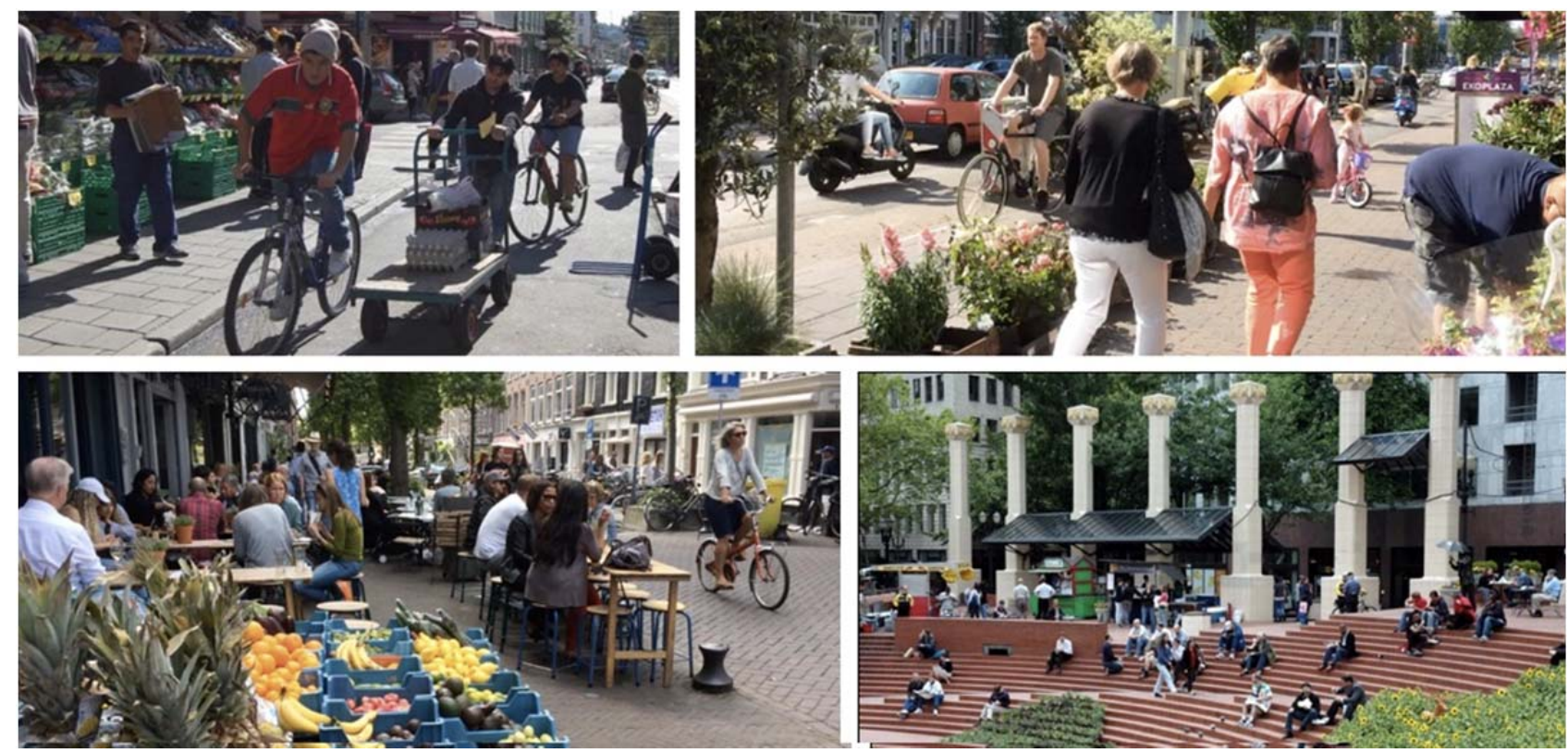

Figure 5.. Public spaces unlock all the things that cities give us. Photos: The Author.

For our own part at the Centre, we are keen to apply research into practice, and in turn, to use practice as the basis of other research that can be shared and applied to better practice elsewhere. This is also a key part of the implementation section in the New Urban Agenda: to engage "academia and research institutions, and their existing networks, to deliver on capacity development programmes."

For example, in 2020 we are launching a new "pattern language for growing regions," a collection of "design patterns" that have emerged from successful practice, and that can be shared, modified and adapted to local conditions. The collection will appear as a print publication, along with an editable wiki "repository," a user-friendly peer-to-peer data platform for capturing and sharing successful practices, exactly as outlined in the New Urban Agenda. 
This, then, is what seems to us necessary to implement the public space mandate within the New Urban Agenda - and to unleash the power of public spaces to provide access, interaction, opportunity, recreation, enjoyment, economic expansion, human development, and all the other things that cities can give us.

\section{References}

Bettencourt, L. (20I3). The Kind of Problem a City is. SFI Working Paper: 20I3-03-008. Santa Fe NM: Santa Fe Institute. Accessed at: https://sfi-edu.s3.amazonaws.com/sfi-edu/production/uploads/sficom/dev/uploads/filer/fa/f6/faf6 I 4 | 8-fc4f-42d5-8c28-dfI I 97a390 I 8/I3-03-008.pdf

Clos, J. (2016). "We have lost the science of building cities." Interview in The Guardian, I8 April 2016. Accessed on December 4, 2017 at https://www.theguardian.com/cities/2016/apr/l8/lost-science-building-cities-joan-clos-unhabitat

Clos, J. (2017). "Housing Policies: Affordable homes message by Dr. Joan Clos, UN-Habitat Executive Director." Accessed at https://reliefweb.int/report/iraq/housing-policiesaffordable-homes-message-dr-joan-clos-un-habitat-executive-director

Clos, J. (2018). Interview at the World Urban Forum, Kuala Lumpur, Malaysia. Accessed at: https://www.youtube.com/watch?v=gCO7vPt96Tk\&list=PLFjow8ghakAxnLj95HLkelVkJHQ HlyDXY\&t=0s\&index $=14$

Jacobs, J. (196I). The Death and Life of Great American Cities. New York: Random House.

Mehaffy and Low (2018). The Resurgence of Public Space: From the Athens Charter to the New Urban Agenda. The Journal of Public Space, 3(3), I-24.

UN-Habitat (2018). The Quito Papers and the New Urban Agenda. New York: UN-Habitat.

United Nations (2017). Resolution adopted by the General Assembly on 23 December 2016: 7I/256, “New Urban Agenda." New York: United Nations (25 January 2017). 